\title{
Induction of Nitric Oxide and TNF- $\alpha$ in Newcastle Disease Virus (NDV) AF2240 Infected RAW 264.7 Macrophages and their Cytotoxic Activity on MDA-MB-231 Breast Cancer Cell Line

\author{
Ismaila Ahmed ${ }^{1,2}$, Umar Ahmad ${ }^{1,3}$, Yong Yoke Keong ${ }^{1,4}$, Nizar Abdu Manan ${ }^{1,4}$ and Fauziah Othman ${ }^{1,4 *}$
}

${ }^{1}$ Research Laboratory of Anatomy and Histology, Faculty of Medicine and Health Sciences, University Putra Malaysia, 43400 Serdang, Selangor, Malaysia ${ }^{2}$ Department of Microbiology, Faculty of Science, Bauchi State University, Gadau, PMB 65, Nigeria

${ }^{3}$ Department of Human Anatomy, Faculty of Medical Sciences, Bauchi State University, Gadau, PMB 65, Nigeria

${ }^{4}$ Department of Human Anatomy, Faculty of Medicine and Health Sciences, University Putra Malaysia, 43400 Serdang, Selangor, Malaysia

\begin{abstract}
Background: It is well known that Newcastle Disease Virus (NDV) AF2240 has antitumor activity against breast cancer cell lines. Several studies have thought this activity depend on direct viral oncolysis, which may not be the only factor that play a role in the antitumor effect of the virus. However, the mechanism underlying its antitumor effect is largely unresolved. In line with this observation, we postulated that NDV AF2240 may induce an in vitro production of Nitric Oxide (NO) and Tumor Necrosis Factor (TNF- $\alpha$ ) in RAW 264.7 macrophages for cytotoxic activity on breast cancer cells.
\end{abstract}

Methods: NDV AF2240 were subjected to different experimental conditions (Live, UV-inactivated and Heatinactivated), different Heamagglutination (HA) titer of the virus were co-cultured with RAW 264.7 cells to get the cell-free supernatant. Levels of TNF- $\alpha$, and NO production were measured by ELISA and Griess assay respectively. MTT assay was later used to determine their cytotoxicity on MDA-MB-231 breast cancer cell line in vitro.

Results: NDV was found to be an excellent inducer in RAW 264.7 macrophage cells of TNF- $\alpha(P<0.05)$ and NO production $(\mathrm{P}<0.05)$ when compared with the negative control. The supernatant containing NO and TNF- $\alpha$ was also found to be cytotoxic against MDA-MB-231 cells $(P<0.05)$ when compared with the negative control, indicating that viral replication was not necessary for their production, because UV-inactivated NDV for 15 minutes was almost as good as lived NDV. However, heat inactivated NDV did not induce TNF- $\alpha$ and NO production.

Conclusion: This suggests the relevance of TNF- $\alpha$ and NO in the indirect antitumor effect of NDV AF2240, and also shown that mare contact between the macrophages and the NDV is enough to induce TNF- $\alpha$ and NO production in macrophages.

Keywords: Newcastle disease virus (NDV); Macrophages; TNF- $\alpha$; NO, Breast Cancer Cell

\section{Introduction}

Newcastle disease virus (NDV) has recently been given more attention because of its antineoplastic and immunostimulatory properties $[1,2]$. It has been used in a phase II clinical trials in which Autologous Tumor Vaccines (ATV) and modified NDV were given to breast cancer patients as a form of post-surgery tumor vaccination $[3,4]$. Interestingly, the therapy was well tolerated as there were no much side effect recorded [3]. NDV is a contagious and deadly viral disease of birds that causes large economic loses to poultry industries worldwide [5]. It is non-segmented, single stranded, negative sense RNA virus belongs to Avulavirus in the Paramyxoviridae family [6]. This virus is one of the numerous naturally occurring oncolytic viruses, which selectively infects, replicate within and kill the tumor cells [7]. For a long time, the therapeutic efficacy was thought to depend on the direct viral oncolysis. However, direct NDV induced cytolysis may not be the only factor that plays a role in anti-tumour efficacy [8]. Understanding how host immune system interacts with the virus to achieve anti-tumor immunity is essential for effective tumor eradication.

Macrophages are capable of producing variety of cytokines against cancer cells, and not only acts as tumor associated antigen presenting cells, but also as cytotoxic effector cells [9], some cytokines such as TNF- $\alpha$ and NO may act synergistically in the cytotoxic damage of tumor cells [8]. Cytotoxicity of NO is usually due to production of peroxynitrite $\left(\mathrm{ONOO}^{-}\right)$[10], which inhibit mitochondrial respiration
[11]. Inducible NO synthase (iNOs) is responsible for biosynthesis of NO by macrophages, however, some cytokines (IF- $\gamma$, LPS, IL- $1 \beta$, IL2) induced iNOs-mRNA syntheses but do not cause NO production by macrophages [12]. TNF- $\alpha$ is a pro-inflammatory cytokines that induces the tumoricidal activity of the macrophages and also stimulates the production of other cytokines by macrophages [13]. The antitumor effect of TNF- $\alpha$ is due to its direct cytotoxic activity and selective destruction to endothelial cells of tumor vascular system, leading to apoptosis and necrosis [14].

Recent study indicated that, Malaysian strain NDV AF2240 was capable of inducing apoptosis in breast cancer cells in vitro, and the apoptotic effect was correlated with the production of pro-inflammatory cytokines [15]. However, the mechanism by which the virus suppresses

*Corresponding author: Fauziah Othman, Department of Human Anatomy, Faculty of Medicine and Health Sciences, University Putra Malaysia, 43400 Serdang, Selangor, Malaysia, Tel:+603-89472315; Fax: 603-89422341; E-mail: fauziah@upm.edu.my

Received September 16, 2014; Accepted November 20, 2014; Published November 29, 2014

Citation: Ahmed I, Ahmad U, Keong YY, Manan NA, Othman F (2014) Induction of Nitric Oxide and TNF- $\alpha$ in Newcastle Disease Virus (NDV) AF2240 Infected RAW 264.7 Macrophages and their Cytotoxic Activity on MDA-MB-231 Breast Cancer Cell Line. J Cancer Sci Ther 6: 478-482. doi:10.4172/1948-5956.1000311

Copyright: $\odot 2014$ Ahmed I, et al. This is an open-access article distributed unde the terms of the Creative Commons Attribution License, which permits unrestricted use, distribution, and reproduction in any medium, provided the original author and source are credited. 
Citation: Ahmed I, Ahmad U, Keong YY, Manan NA, Othman F (2014) Induction of Nitric Oxide and TNF- $\alpha$ in Newcastle Disease Virus (NDV) AF2240 Infected RAW 264.7 Macrophages and their Cytotoxic Activity on MDA-MB-231 Breast Cancer Cell Line. J Cancer Sci Ther 6: 478-482. doi:10.4172/1948-5956.1000311

the breast cancer cells is largely unknown. It is also unclear whether NDV AF2240 may activate macrophages to produce NO and TNF for cytotoxic activity against breast cancer cells. To address this question, we study NO and TNF production in NDV activated RAW 264.7 macrophage cell line, where we investigated the cytotoxicity of the NO and TNF in breast cancer cells in vitro.

\section{Materials and Methods}

\section{Propagation and purification of NDV AF2240 strain}

The strain of NDV AF2240 was obtained from virology laboratory Faculty of Veterinary Medicine, Universiti Putra Malaysia (UPM). The virus was then propagated in the allantoic fluid of specific pathogen free (SPF) 9-11 day old embryonated chicken eggs according to the protocol of Blaskovic and Styk et al. [16].

The fluid enriched with NDV virions were harvested at 96 hours after infection, and the presence of the virus was confirmed using haemagglutination spot test with chicken red blood cells (RBC) as described below. The fluid was purified as described previously [3], clarified first with high speed refrigerator centrifuge at $4^{\circ} \mathrm{C}$ for 10 minutes. The supernatant was centrifuged at 20,000 rpm (Beckman Coulter, USA, Avanti J-26 XPI) for 3 hours at $4^{\circ} \mathrm{C}$. Dounce homogenizer was used to resuspend the pellet before dissolving in $1 \mathrm{ml}$ NTE buffer (0.5 M NaCl, $10 \mathrm{mM}$ Tris-HCl, and $5 \mathrm{mM}$ EDTA, $\mathrm{pH}$ 8.0). Sucrose gradients of $30 \%, 40 \%, 50 \%$ and $60 \%$ concentration were aliquoted into the ultra-clear tubes in descending order using $1 \mathrm{ml}$ syringe before kept at $4^{\circ} \mathrm{C}$ overnight, followed by gentle addition of the virus into the sucrose gradient. The sucrose gradient with the virus was centrifuged at 40,000 rpm SW41 Ti rotor (Beckman Coulter, USA) for 4 hours at $4^{\circ} \mathrm{C}$. Band of the virus was observed between $50 \%$ and $60 \%$ sucrose gradient under light, and marked with a marker pen. The virus band was then aspirated with a sterile $1 \mathrm{ml}$ syringe (Terumo syringe) and transferred into a polyalomer tubes (Beckman Coulter, USA). The polyalomer tubes were filled with NTE buffer before another centrifugation was done at $35,000 \mathrm{rpm}$ for 2 hours at $4^{\circ} \mathrm{C}$ to remove the remaining sucrose. The supernatant was discarded, and the pellet was dissolved in 500 $\mu \mathrm{l}$ NTE buffer, filtered with $0.45 \mu \mathrm{m}$ filter (Sartorius Stedim Biotech, France) and kept in Eppendorf tubes at $-80^{\circ} \mathrm{C}$ for further used.

\section{Heamagglutination test (HA)}

The titre of the virus was determined by Heamagglutination (HA) test, using U-bottom 96-well plate (Eppendorf, Germany). $50 \mu \mathrm{l}$ of PBS was added into the second well of the plate until the $24^{\text {th }}$ well, while the first well was loaded with $10 \mu \mathrm{l}$ of purified viruses diluted with 90 $\mu \mathrm{l}$ of PBS to get a total of $100 \mu \mathrm{l}$ viral suspension. $50 \mu \mathrm{l}$ of the viral suspension from the first well were aspirated and added to the $2^{\text {nd }}$ well, resuspended, before another $50 \mu \mathrm{l}$ was taken from the $2^{\text {nd }}$ to the $3^{\text {rd }}$ continuously to perform serial dilution until the $23^{\text {rd }}$ well of the plate. Then, $50 \mu \mathrm{l}$ of the chicken RBC $(0.5 \%)$ was added to all the wells in the plate, resuspended, and kept for about 30 minutes at room temperature. The appearance of the red button (Spot) was observed at the bottom of the plate, and the reciprocal of the most diluted concentration of the virus that agglutinated the $\mathrm{RBC}$ was taken as the virus $\mathrm{HA}$ titre.

\section{Viral inactivation}

The UV-inactivation of NDV AF2240 was done according to the method described by Jinyang Zeng et al. [17]. Different HA titre of NDV AF2240 strain were aliquoted into petri dishes before exposure to ultraviolent light source $\left(245 \mathrm{~nm}, \mathrm{~mW} / \mathrm{cm}^{2}\right)$ for 15 minutes at a distance of $7 \mathrm{~cm}$ from the UV source. The heat-inactivation of the virus was done according to Sofer et al. [18] by placing the petri dishes in hot air oven at $60^{\circ} \mathrm{C}$ for 10 minutes.

\section{Cells and cell cultures}

The human breast cancer cell line MDA-MB-231(ATCC ${ }^{\circ}$ HTB26") was purchased from American Type Culture Collection, and macrophage cell line RAW 264.7 was kindly provided by Dr. Yong Yoke Keong, Unit of Physiology, Department of Human Anatomy, Faculty of Medicine and Health Sciences, University Putra Malaysia (UPM). The cells were grown successfully as monolayer using 75 and $25 \mathrm{~cm}^{2}$ culture flasks in a humidified incubator of $5 \% \mathrm{CO}_{2}$ at $37^{\circ} \mathrm{C}$. Cells were supplemented with $10 \%$ foetal bovine serum (FBS) (Gibco invitrogen") and 1\% penicillin/streptomycin in DMEM media (Gibco") before the incubation.

\section{Co-culture of NDV with RAW 264.7 macrophage}

The virus was serially diluted with phosphate buffer saline (PBS) in order to obtain the different $\mathrm{HA}$ titer of $2 \mathrm{HA}, 4 \mathrm{HA}, 8 \mathrm{HA}, 16 \mathrm{HA}$, $32 \mathrm{HA}$ and $64 \mathrm{HA} ; 100 \mu \mathrm{l}$ of each titre was used to infect the RAW 264.7 macrophage cell line of about $90-95 \%$ confluence. The cells were incubated at $37^{\circ} \mathrm{C}$ supplied with $5 \% \mathrm{CO}_{2}$ for 24 hours. Cell scraper was used to detach the adhered cells before aspirated into a conical centrifuge tube for centrifugation at $1000 \mathrm{rpm}$ for 10 minutes. The supernatant was collected and frozen at $-80^{\circ} \mathrm{C}$, the cell pellet were washed in PBS and resuspended in $1 \mathrm{ml}$ DMEM medium. Cells were then frozen and thawed three times before further centrifugation at $1000 \mathrm{rpm}$ for $10 \mathrm{~min}$ to get the supernatant again, which was later used as experimental samples.

\section{Quantification of TNF- $\alpha$ in cell culture supernatant}

TNF- $\alpha$ protein production in the cell culture supernatant was measured by using an enzyme linked immunosorbent assay (ELISA) kit (Cayman Chemical Company). All the protocols were based on the manufacturer's instructions and recommendations. Recombinant TNF- $\alpha$ was used as standard, and the assay sensitivity was $2.9 \mathrm{pg} / \mathrm{ml}$.

\section{Quantification of nitric oxide from cell culture supernatant}

Nitric Oxide (NO) production in the cell culture supernatant was measured as the sum of nitrate $\left(\mathrm{NO}_{3}{ }^{-}\right)$and nitrite $\left(\mathrm{NO}_{2}{ }^{-}\right)$using Cayman's Nitrate/Nitrite Calorimetric assay Kit according to manufacturer's instructions. $80 \mu \mathrm{l}$ aliquots of the supernatant were removed and mixed with $10 \mu \mathrm{l}$ enzyme cofactor, and $10 \mu \mathrm{l}$ nitrate reductase before incubated at room temperature for 2 hours. $50 \mu$ of Griess reagent R1 and R2 were added immediately. Absorbance was measured at 540 and $550 \mathrm{~nm}$ respectively.

\section{MTT cytotoxicity assay}

Cytotoxicity was measured by MTT assay base on the description of the manufacturer's protocol (Cayman Chemical). Briefly, $100 \mu$ of MDA-MB-231 cells suspension of $1.3 \times 10^{6}$ cells $/ \mathrm{ml}$ concentration were seeded into the 96-well plate and incubated overnight to allow for their adherence. The culture medium was aspirated and discarded, followed by treatment of the cells with $100 \mu \mathrm{l}$ of the supernatant containing the NO and TNF- $\alpha$, untreated cells serves as the negative control. 24 hours after incubation at $37^{\circ} \mathrm{C}$ and $5 \% \mathrm{CO}_{2}, 10 \mu \mathrm{l}$ of MTT reagent was added to each well and incubated for four hours, $100 \mu \mathrm{l}$ of the crystal dissolving solution was added. Absorbance was measured at $570 \mathrm{~nm}$ using microplate reader. Three independent experiments were conducted and the percentage of cell viability was determined using the formula below: 
“\% Cell Viability $=$ OD of sample $\div$ OD of control $\times 100 \% "$

Cytotoxicity $=100$-cell viability.

\section{Statistical analysis}

The data obtained from TNF- $\alpha$ and NO production were analysed using one-way ANOVA, multiple comparison were tested using Tukey's test. Analysis of data was conducted using GraphPad Prism (Version 6.0) for windows (GraphPad Software, San Diego, California, USA) and $p<0.05$ was considered as statistically significance.

\section{Results}

\section{In vitro induction of TNF- $\alpha$ by NDV AF2240}

In order to investigate whether NDV AF2240 is capable of inducing TNF- $\alpha$ production, enzyme linked immunosorbent assay (ELISA) was performed on the supernatant obtained from RAW 264.7 macrophages cells, which have been cultured in the presence of live NDV, UVinactivated NDV, heat inactivated NDV and in medium alone to serve as a control. Different HA titre of the virus were used in all the three groups, absorbance were measured at $420 \mathrm{~nm}$. In the supernatant obtained from lived NDV infected cells, a noticeable production of TNF- $\alpha$ at $2 \mathrm{HA}$ (from 0 to $1.22 \mathrm{pg} / \mathrm{ml}$ ) and a steady increase to the most significant value at $64 \mathrm{HA}$ (from 0 to $3.62 \mathrm{pg} / \mathrm{ml}$ ) when compared with the negative control $(P<0.05)$, (Figure 1). Similarly, in the case of UV-inactivated NDV, there was also a production of TNF- $\alpha$ with the highest production at $64 \mathrm{HA}$ and the lowest at $2 \mathrm{HA}$, but clearly shorter and lower than the one with live NDV, however, the supernatant from cell culture for heated inactivated NDV, shows a very small TNF production $(P>0.05)$ in all the HA titres used in the experiment.

\section{Induction of NO by NDV AF2240 in vitro}

NDV induces NO production in RAW 264.7 macrophages in vitro, after incubating the RAW macrophages in the presence of live $\mathrm{NDV}$, the level of NO in the supernatant obtained was found to be increasing with increased in HA titre (Figure 2). A statistical significant changes were observed, with the maximum effect at 64HA (from 0 to $19.9 \mu \mathrm{M} / 80 \mu \mathrm{l}$ of supernatant) $P<0.05$ when compared with the negative control. UV-inactivated NDV which is known to lose the ability of infecting the cells, but also bind to the cell surface [19], had also enhanced NO production from macrophages cells (from 0 to 15.33 $\mu \mathrm{M} / 80 \mu \mathrm{l}$ supernatant) $P<0.05$ but, much lower than the live NDV. However, incubating the cells with heated inactivated NDV, which may no longer bind to the cells-surface due to denaturation, could not induced any NO production in the macrophages in all the virus titre used when compared with the negative control.

\section{Cytotoxic effect of TNF and NO from macrophages supernatant on MDA-MB-231}

The cytotoxicity of the supernatant on MDA-MB-231 cells was investigated using MTT assay. After treatment with the supernatant for 24 hours, the viability of cells decreases from $100 \%$ to $14.2 \%$ and $17 \%$ for Lived NDV and UV-inactivated NDV supernatant respectively, but no cytotoxic effects was observed for heated inactivated NDV supernatant (Figure 3). There was significant decrease of viable cells in the virus titre as low as $8 \mathrm{HA}$, until 64HA for supernatant of lived and UV-inactivated but no significant effects was seen for heated inactivated NDV (Figure 3). The result indicated that TNF- $\alpha$ and NO containing supernatant can significantly induced cytotoxicity on MDA-MB-231 cells in a dose dependent manner.

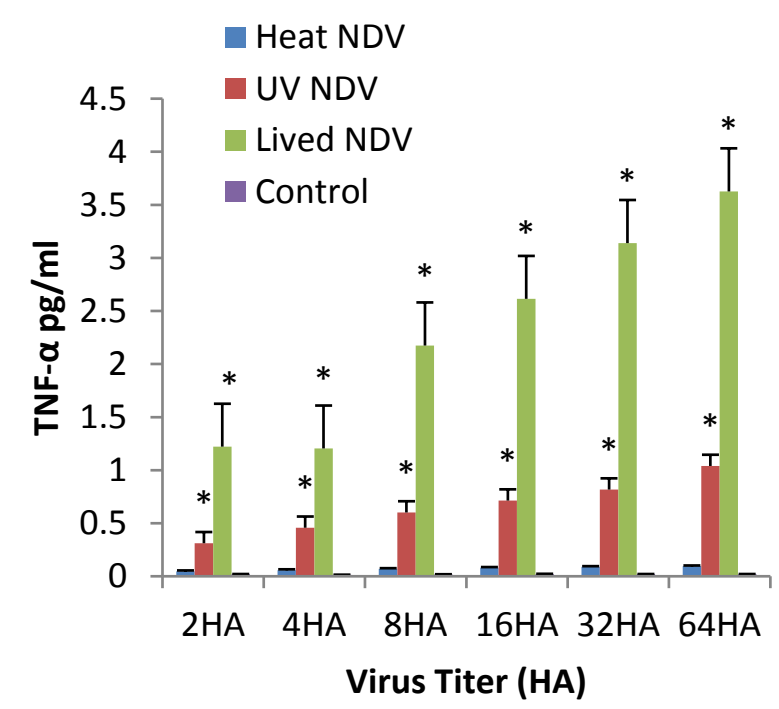

Figure 1: Shows the effect of different dose of lived, UV-inactivated, and heatinactivated NDV AF2240 on TNF- $\alpha$ induction in RAW 264.7 macrophages cells. Cells were co-cultured for 24 hours with different HA of the virus, the level of TNF- $\alpha$ in the culture supernatants were determined by ELISA. Data were expressed as mean \pm SEM ${ }^{*} P<0.05$ when compared with the negative control.

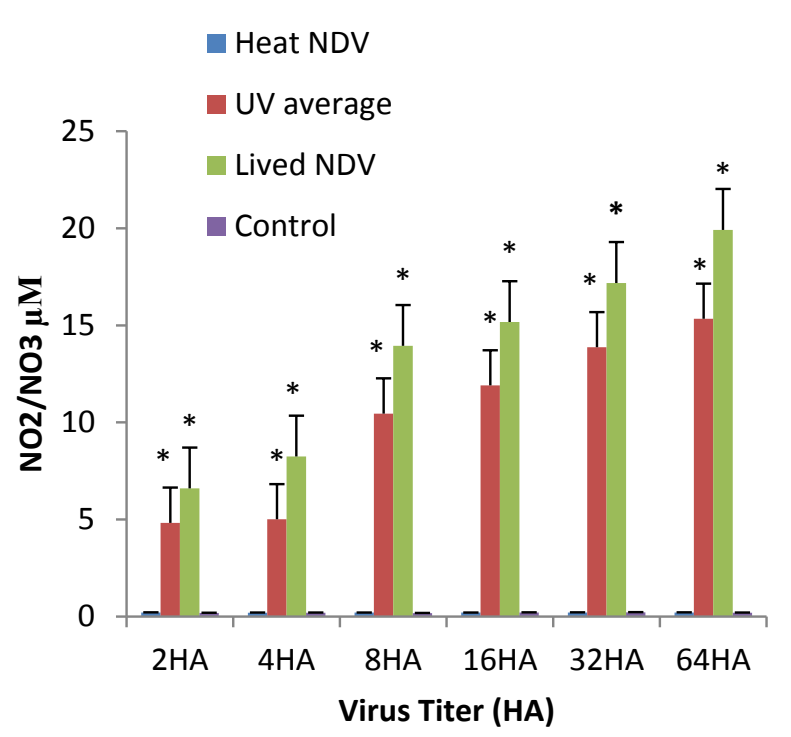

Figure 2: Shows the effect of different dose of lived NDV, UV-NDV, and heatinactivated NDV AF2240 on NO induction on RAW 264.7 macrophages cells. Cells were co-cultured for 24 hours with different HA of the virus, the level of $\mathrm{NO}$ in the culture supernatants were measured as a sum of nitrate and nitrite using calorimetric assay with Griess reagent. Data were expressed as mean \pm SEM ${ }^{*} P<0.05$ when compared with the negative control.

\section{Discussion}

In this research, we investigated the immunostimulatory capacity of NDV AF2240, our interest was focused on NDV because, it's live form has been used in clinics for more than 20 years and successful results were claimed with little or no side effects on breast cancer patients [20]. Two important findings were made based on the mechanism through which NDV induced cytotoxic effects on cancer cells; NDV AF2240 strain was found to be an excellent elicitor of NO and TNF- $\alpha$ in 


\section{Cytotoxicity (MTT) Assay}

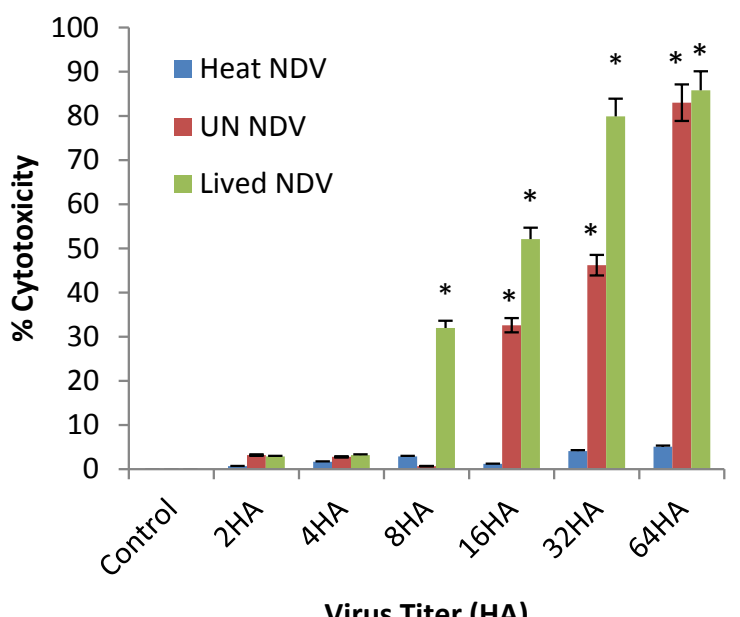

Figure 3: The percentage of Cell cytotoxicity of MDA-MB-231 Cells after treatment with TNF and NO containing supernatant. Data were expressed as mean \pm SEM. of three experiments. Significant difference from untreated control are shown by ${ }^{*} P<0.05$.

RAW 264.7 macrophages, the supernatant containing NO and TNF- $\alpha$ obtained from NDV infected RAW 264.7 was also found to exhibit significant cytotoxic effect on MDA-MB-231 breast cancer cell line.

One other study have demonstrated that NDV AF2240 has an oncolytic effect against breast cancer cells, and can be used to generate tumor vaccine for active immunotherapy of breast metastasis [15]. However, the mechanism for this oncolytic activity is not clearly elucidated. The main objective of this research was to determine whether NDV AF2240 can induce the production of NO and TNF in RAW 264.7 macrophages in vitro, and to see the cytotoxic effect of these cytokines generated by NDV AF2240 on MDA-MB-231 breast cancer cell line.

This finding indicated that, treatment of RAW 264.7 macrophages with live NDV and UV- inactivated NDV resulted in significant increase in both NO and TNF- $\alpha$ production, but heated inactivated NDV does not show any significant production in both cases. Since UV-inactivated NDV that can only bind to the macrophages, but does not infect the cells, was able to cause NO and TNF-a production, and the heat inactivated NDV which cannot bind to the cell surface could not show any of these effects. Base on this findings, therefore, it can be deduced that the binding of the NDV to the cells was enough to stimulate NO and TNF production. Mere binding of NDV and RAW 264.7 macrophages transmit signals which causes NO and TNF- $\alpha$ production, and the detail of the signalling requirement for their production have to be further investigated.

Similar study by schirrmacher et al. [21] also showed that NDV infection of macrophages causes up-regulation of macrophage enzymes (ADA, iNOs, lysozymes) and the release of effector molecules such as NO and TNF- $\alpha$ in the macrophage supernatant, and that repeated intravenous transfer of NDV activated macrophages exerted significant suppressive effect on pulmonary metastasis in lung carcinoma model.

Previous research showed that AF2240 exhibits cytolytic effect on CEM-SS (Human T-lymphoblastic), MDA-231 and MCF-7 breast cancer cell lines, but does not affect normal mouse fibroblast (3T3) cells [22]. NDV V4UPM strain was also shown to exert cytolytic effect on MCF-7 and MDA-231, in fact a lot of NDV strains were found to be cytolytic against many human cancer cell lines. However, all their research did not explain whether the oncolytic effect is from the direct effect of the virus or not. The most important observation in this article is that, NDV AF2240 is a potential inducer of NO and TNF- $\alpha$ in macrophages in vitro. Significant cytotoxicity was observed after treatment of MDA-MB-231 cells with NO and TNF- $\alpha$ containing supernatant obtained from NDV infected RAW 264.7 macrophages. This has demonstrated that either NO, TNF- $\alpha$ or both play an important role in the indirect oncolytic effect of NDV AF2240 on breast cancer cell line.

Therefore, conclusively, our result signified that NDV AF2240 induced NO and TNF- $\alpha$ production in RAW 264.7 macrophage cells, and that these cytokines contribute to the cytotoxic effect of the virus on MDA-MB-231 breast cancer cells in vitro. Further study need to be carryout to find out whether the cytotoxicity is from NO, TNF- $\alpha$ or both.

\section{Acknowledgments}

This study was supported by funding from the Research University Grants (RUGs), Universiti Putra Malaysia, under the grant number(s): 9367600. The authors are thankful to Mr. Mohd Kamarudin bin Awang Isa of the Biologic Unit of Virology Laboratory, Faculty of Veterinary Medicine, Universiti Putra Malaysia (UPM) for his technical assistance during the viral propagation and purification.

\section{References}

1. Washburn B, Weigand MA, Grosse-Wilde A, Janke M, Stahl H, et al. (2003) TNF-Related Apoptosis-Inducing Ligand Mediates Tumoricidal Activity of Human Monocytes Stimulated by Newcastle Disease Virus. J Immunol 170: 1814-1821.

2. Umansky V, Shatrov VA, Lehmann V, Schirrmacher V (1996) Induction of NO synthesis in macrophages by Newcastle disease virus is associated with activation of nuclear factor-kappa B. Int Immunol 8: 491-498.

3. Schirrmacher V, Ahlert T, Pröbstle T, Steiner HH, Herold-Mende C, et al. (1998) Immunization with virus-modified tumor cells. Semin Oncol 25: 677-696.

4. Cassel WA, Murray DR (1992) A ten-year follow-up on stage II malignan melanoma patients treated postsurgically with Newcastle disease virus oncolysate. Med Oncol Tumor Pharmacother 9: 169-171.

5. Omar AR, Ideris A, Ali AM, Othman F, Yusoff K, et al. (2003) An overview on the development of newcastle disease virus as an anti-cancer therapy. Malays J Med Sci 10: 4-12.

6. Alexander DJ (2000) Newcastle disease and other avian paramyxoviruses. Rev Sci Tech 19: 443-462.

7. Fournier $P$, Wilden $H$, Schirrmacher $V$ (2012) Importance of retinoic acidinducible gene I and of receptor for type I interferon for cellular resistance to infection by Newcastle disease virus. Int J Oncol 40: 287-298.

8. Siziopikou KP, Harris JE, Casey L, Nawas Y, Braun DP (1991) Impaired tumoricidal function of alveolar macrophages from patients with non-small cell lung cancer. Cancer 68: 1035-1044.

9. Mantovani A, Bottazzi B, Colotta F, Sozzani S, Ruco L (1992) The origin and function of tumor-associated macrophages. Immunol Today 13: 265-270.

10. Brown GC (2001) Regulation of mitochondrial respiration by nitric oxide inhibition of cytochrome c oxidase. Biochim Biophys Acta 1504: 46-57.

11. Allione A, Bernabei P, Bosticardo M, Ariotti S, Forni G, et al. (1999) Nitric oxide suppresses human $\mathrm{T}$ lymphocyte proliferation through IFN-gamma-dependent and IFN-gamma-independent induction of apoptosis. J Immunol 163: 41824191.

12. Albina JE (1995) On the expression of nitric oxide synthase by human macrophages. Why no NO? J Leukoc Biol 58: 643-649.

13. Shau H (1988) Characteristics and mechanism of neutrophil-mediated cytostasis induced by tumor necrosis factor. J Immunol 141: 234-240. 
Citation: Ahmed I, Ahmad U, Keong YY, Manan NA, Othman F (2014) Induction of Nitric Oxide and TNF- $\alpha$ in Newcastle Disease Virus (NDV) AF2240 Infected RAW 264.7 Macrophages and their Cytotoxic Activity on MDA-MB-231 Breast Cancer Cell Line. J Cancer Sci Ther 6: 478-482. doi:10.4172/1948-5956.1000311

14. Lejeune FJ, Rüegg C, Liénard D (1998) Clinical applications of TNF-alpha in cancer. Curr Opin Immunol 10: 573-580.

15. Fauziah O, Aini I, Gholamreza M, Zulkapli Bt. E, Asmah R (2010) Oncolytic Effect of Newcastle Disease Virus AF2240 Strain on MCF-7 Breast Cancer Cel Line. Yakhteh Medical Journal 12: 17-24.

16. Blaskovic D, Styk B (1967) Laboratory methods of viral transmission in multicellular organisms. Methodes in virology 1: 194-197.

17. Zeng J, Fournier P, Schirrmacher V (2002) Induction of Interferon-a and Tumor Necrosis Factor-Related Apoptosis-Inducing Ligand in Human Blood Mononuclear Cells by Hemagglutinin-Neuraminidase but Not $F$ protein of Nwecastle Disease Virus. Virology 297: 19-30.

18. Gail S, Dorothy CL, Jeri AB (2003) Inactivation Methods Grouped by Virus BioPharm International 16: 45-51.
19. Jurianz K, Haas C, Hubbe M, Ertel C, Brunner G, et al. (1995) Adhesive function of newcastle-disease virus hemagglutinin in tumor-host interaction. Int J Oncol 7: 539-545.

20. Cassel WA, Murray DR (1986) Viral Oncolysates in the treatment of regional metastasis of melanoma. In: Larson DL, Guillamondegui OM, Ballantyne AJ, eds. Cancer in the neck: evaluation and treatment. New York: Macmillan, 235242.

21. Schirrmacher V, Bai L, Umansky V, Yu L, Xing Y, et al. (2000) Newcastle disease virus activates macrophages for anti-tumor activity. Int $\mathrm{J}$ Oncol 16: 363-373.

22. Rola A, Aied MA, Abdul MA, Aini I, Abdul R, et al. (2011) Apoptosis Induction and Cytolytic Effects of Newcastle Disease Virus Strain AF2240 on DBTRG.05 mg Brain Tumor Cell Line. International Journal oh Cancer Research 7: 25-35. 